\title{
Inhibitory Effect of $\alpha$-Pinene on SGC-7901 Cell Proliferation and the Mechanism of ATM Kinase Signaling Pathway
}

\author{
Fuhong Zhu' ${ }^{1}$, Fengxiang Wei ${ }^{2}$, Cui Zhang1* \\ ${ }^{1}$ Department of Immunology, School of Basic Course, Guangdong Pharmaceutical University, Guangzhou, \\ China \\ ${ }^{2}$ Central Laboratory, Longgang Maternity and Child Health Care Hospital, Shenzhen, China \\ Email: ${ }^{*}$ ccuizhang@126.com
}

Received 10 February 2015; accepted 7 March 2015; published 11 March 2015

Copyright (C) 2015 by authors and Scientific Research Publishing Inc.

This work is licensed under the Creative Commons Attribution International License (CC BY).

http://creativecommons.org/licenses/by/4.0/

c) (i) Open Access

\begin{abstract}
Objective: To research the inhibitory effect on SGC-7901 cells of $\alpha$-pinene, and the related mechanism of $\alpha$-pinene. Methods: Used the MTT method to detect inhibition rate and western blotting to detect the influence on expression of ATM, Phos-S1981ATM, H2AX, $\gamma H 2 A X, C H K 2$ and p-CHK2, p53 and phos-p53 cell cycle related protein in SGC-7901 cells. Results: The research found $\alpha$-pinene could inhibit the proliferation of SGC-7901 cells observably in vitro, and the inhibition rate assumes the dependence on concentration; and western blotting results showed that, $\alpha$-pinene could activate phospho-ATM, increase the amount of $\gamma \mathrm{H} 2 \mathrm{AX}(p<0.05, p<0.05)$; increase the expression of p-CHK2, p53 and phos-p53 ( $p<0.05, p<0.05, p<0.05)$; But there is no significant effect on expression of CHK2 $(p>0.05)$. Conclusions: $\alpha$-pinene could inhibit the proliferation of SGC-7901 cells, and by inducing ATM (Ataxia Telangiectasia-Mutated) kinase signal pathway in DNA damage response, activating cell cycle checkpoint, making the cell cycle arrest then exerts its anti-tumor effects.
\end{abstract}

\section{Keywords}

$\alpha$-Pinene, SGC-7901 Cells, ATM Kinase, Proliferation, Cell Cycle, DNA Damage

\section{Introduction}

Gastric cancer is a malignant disease which has had a serious impact on human health. Finding highly efficient

"Corresponding author.

How to cite this paper: Zhu, F.H., Wei, F.X. and Zhang, C. (2015) Inhibitory Effect of $\alpha$-Pinene on SGC-7901 Cell Proliferation and the Mechanism of ATM Kinase Signaling Pathway. Chinese Medicine, 6, 27-33.

http://dx.doi.org/10.4236/cm.2015.61004 
and low or non-toxic compounds from within Chinese medicine to treat gastric cancer has been a topic of interest in Eastern oncology. From within Chinese medicine, it has been long known that the crude extract of pine needle oil has the potential to delay aging by dissolving compounds that accumulate as the body ages, as well as generally promote body function, and immunity [1]. ATM kinase is one moderator that maintains genome stability and plays a critical role in DNA damage response. ATM kinase signal pathway is closely linked to tumor initiation and development. When DNA is damaged, ATM induces the activation of various substrates that allow the regulation of cell cycle apoptosis, arrest or repair [2]. By studying the $\alpha$-pinene anti-tumor effect in vitro and discussing ATM signal pathway mechanism, our research aims to discuss $\alpha$-pinene [3]-[5], the pine needles' [6] extract, has influence on inhibiting the gastric cancer SGC-7901 cells proliferate and its related mechanism, to provide theory and experimental basis for developing and using $\alpha$-pinene.

\section{Materials and Methods}

\subsection{Reagents and Instruments}

Gastric cancer SGC-7901 cells, $\alpha$-pinene and PTX (paclitaxel), all presented by the basic school of university of JiaMuSi; MTT (Methyl thiazolyl tetrazolium), antibodies, all purchased by cell signaling company; And prepared culture medium diluted to the required concentration; Heracell incubator, Thermo Forma Corp; Inverted microscope, Leica Corp; Enzyme-linked Immuno-metric meter, Bio-Rad Corp; Level-perpendicular plate electrophoresis and electrotransfer devices, Bio-Rad Corp; DU800 protein-nuclenic acid analysis meter, Beckman Corp.

\subsection{Experiment Methods}

\subsubsection{Effect of $\alpha$-Pinene to Gastric Cancer SGC-7901 Cell}

SGC-7901 cells were serially cultured with RPMI-1640 medium which containing $10 \%$ FBS, $1 \%$ penicillin streptomycin combination under the condition of $5 \% \mathrm{CO}_{2}, 37^{\circ} \mathrm{C}$. A well growing SGC-7901 cell was chosen and digested using $0.25 \%$ trypsin, adjusting the density $1 \times 10^{5}$ cells $/ \mathrm{ml}$ with RPMI-1640 medium that contain $10 \%$ FBS, inoculating to 96 well cell culture plate, and $0.1 \mathrm{ml}$ per well, added different levels of $\alpha$-pinene and PTX which prepared with RPMI-1640 medium, the final concentration were $0,0.2,0.4,0.6,0.8$ and $1.0 \mu \mathrm{g} / \mathrm{ml}$, respectively, and eight repeated well every level. A group was set up control group (not contained drug) and DMSO group was blank group (0.05\% DMSO, medium). All cultures continued to cultivate for 24 hours, $\alpha$-pinene group and PTX group supposed to be B group and C group, and PTX group was positive group, to test SGC-7901 cells proliferating inhibition after treated with drugs by MTT assay. Using enzyme-linked immunometric meter to determinate the light absorbance value (A) at $490 \mathrm{~nm}$ wavelength, the cell inhibition ratio was calculated with the following:

$$
\text { Inhibition Ratio }(\%)=(\text { A control }-\mathrm{A} \text { experiment }) /(\mathrm{A} \text { control }-\mathrm{A} \text { blank }) \times 100 \% \text {. }
$$

\subsubsection{Detection the Expression of Related Proteins of SGC-7901 Cells}

Making the logarithmic phase SGC-7901 cell digesting with $0.25 \%$ trypsin, then adjusting the density $1 \times 10^{5}$ cells/ml with medium that contain $10 \%$ FBS, and then inoculating to 6 well cell culture plate, $2 \mathrm{ml}$ per well, After 24 hours, adding different levels of $\alpha$-pinene which prepared with RPMI-1640 medium, the final concentration were $0,0.2,0.4,0.6$ and $0.8 \mu \mathrm{g} / \mathrm{ml}$, respectively. Continuing to culture cells 24 hours, collecting each group's cells, cells were lysed in a buffer $30 \mu \mathrm{g}$ of total cell lysate, based on the standard curve to calculate the sample volume required. Be separated on SDS-PAGE gel and transferred onto nitrocellulose Membranes. Membranes were blocked with 5\% skim milk and then incubated with the indicated rabbit primary antibodies at $4^{\circ} \mathrm{C}$ for overnight. The goat-anti-rabbit second antibody incubating 1 hour at room temperature. Signals were detected using an ECL Western Blotting Kit. Primary antibodies used were: anti-ATM, anti-phospho-ATM (S1981), anti-p53, anti-phospho-p53(S15), anti-H2AX, anti- $\gamma$ H2AX (S139), anti-CHK2, anti-phospho-CHK2 (S345) and anti-actin. Adopted Quantity One 4.6.2 software analysis band signals.

\subsubsection{Statistical Analysis}

Test results were represented by means \pm standard errors, data was analyzed using the SPSS17.0 software, statistical methods such as analysis of variance, paired sample $t$ test and t-test for independent samples were used for testing and analysis, $p<0.05$ represented statistical significance. 


\section{Results}

\subsection{The Inhibiting Effect of SGC-7901 Cells after Treated by $\alpha$-Pinene}

Firstly, each group SGC-7901 cells' morphological changes after treated with different concentrations of $\alpha$-pinene after 24 hours was observed. A group was as normal as control group and cells grew normally in this group. B group was treated by $\alpha$-pinene. SGC-7901 cells morphological changes could be observed when the concentration of $0.4-0.8 \mu \mathrm{g} / \mathrm{ml}$, cells became smaller, Cytoplasmic shrinkage, round and the amount of cells decreased significantly; C group as positive control (PTX group), was almost the same as $\alpha$-pinene group (Figure 1).

Detection of inhibiting ratio of SGC-7901 cells after treated by $\alpha$-pinene, the inhibition ratio gradually increased with the increasing of concentration of $\alpha$-pinene, while the concentration of $\alpha$-pinene was $0.4 \mu \mathrm{g} / \mathrm{ml}$, compared with the A group (no drug treatment) $(p<0.05)$; with the increasing of concentration of $\alpha$-pinene, the inhibition ratio was increased, when concentration of $\alpha$-pinene was $0.8 \mu \mathrm{g} / \mathrm{ml}$ reached the highest ratio, that illustrated the inhibition ratio assumed a dose-dependent manner when concentration of $\alpha$-pinene between $0.4 \mu \mathrm{g} / \mathrm{ml}$ and $0.8 \mu \mathrm{g} / \mathrm{ml}$. Then the ratio started to level out, the inhibition of trends the same as the positive control group, There was no statistical difference between the two groups $(p>0.05)$ (Figure 2).
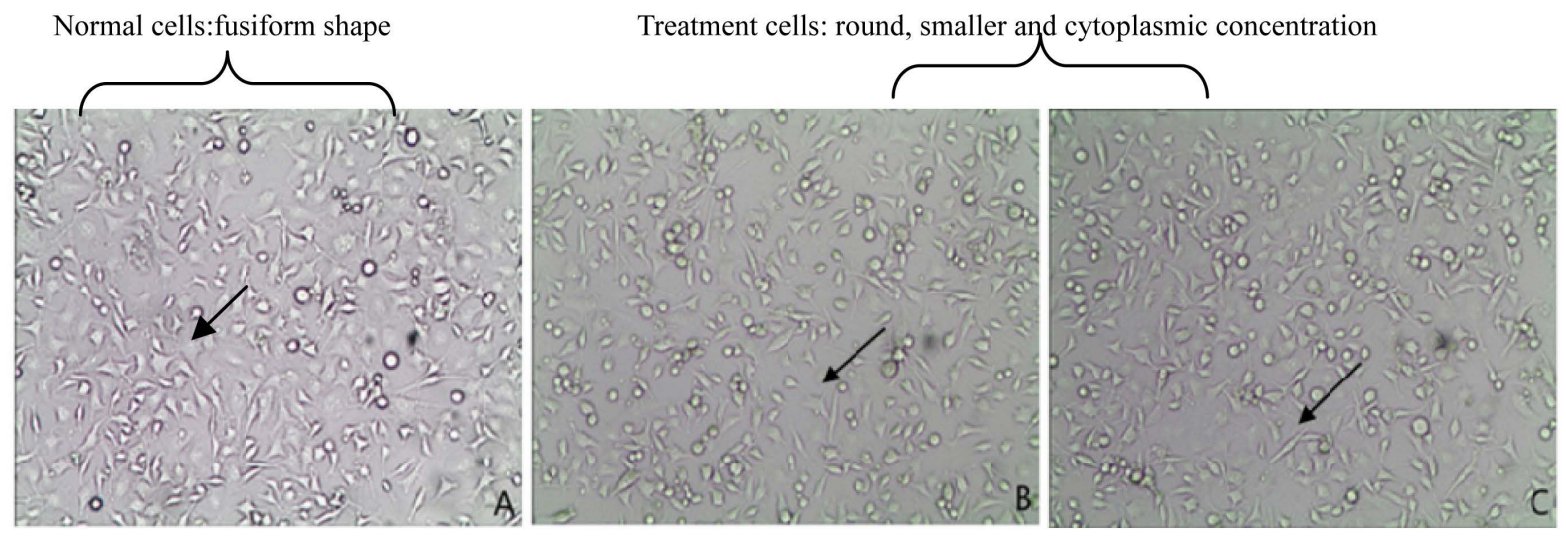

A: normal SGC-7901cells group; B: $\alpha$-pinene group; C: PTX group

Figure 1. $\alpha$-pinene effects on SGC-7901 cells morphology $(10 \times 10)$. SGC-7901 from human gastric cancer cells, A group: normal cells fusiform, growth is good; B group: cells of $\alpha$-pinene treatment became round, smaller, cell shrinkage, C group: morphological changes are similar with $\alpha$-pinene group.

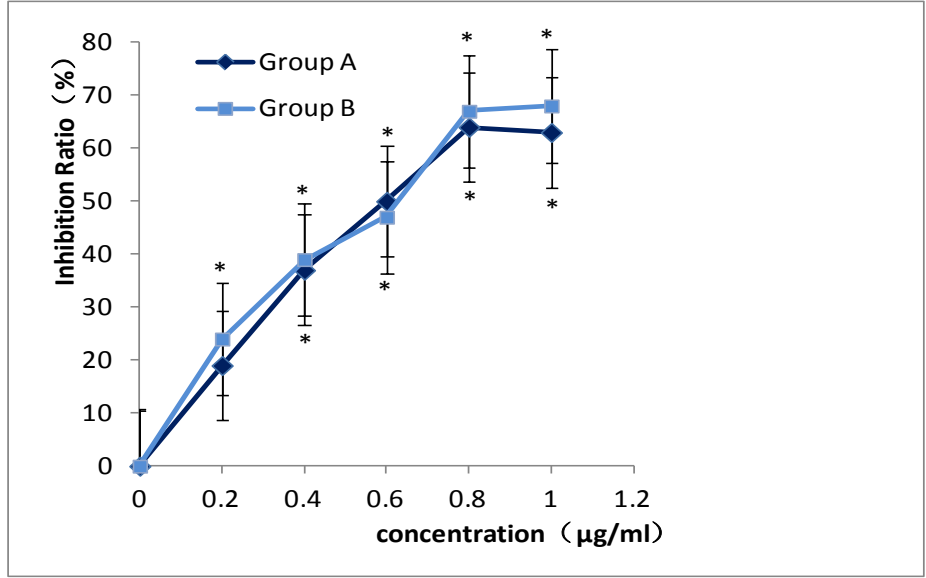

Figure 2. Different concentrations of $\alpha$-pinene and PTX effect on SGC-7901 cell proliferation. While the concentration of $\alpha$-pinene was $0.4 \mu \mathrm{g} / \mathrm{ml}$, A group Significantly different from control group $(p<0.05)$; while the concentration of $\alpha$-pinene was $0.8 \mu \mathrm{g} / \mathrm{ml}$, the max inhibition ratio was $64 \%$, and inhibition ratio no longer elevated when drug concentration continued to increase, The trend of the inhibition ratio in accordance with PTX group. Data were graphed as means \pm standard errors. ${ }^{*}$ : $p<0.05$ in comparison to control cells. 


\subsection{The Expression of Related Proteins in the ATM Kinase Signal Pathway}

Within the SGC-7901 cells that were given $\alpha$-pinene of concentrations are $0,0.2,0.4,0.6$ and $0.8 \mu \mathrm{g} / \mathrm{ml}$, and detected of the contents of ATM, Phos-S1981ATM, H2AX, $\gamma$ H2AX, Chk2, p-Chk2, p53 and phos-p53 after 24 hours. As results displayed, while treated SGC-7901 cells with $\alpha$-pinene 24 hours, with the drug concentration rised, the damage signals phosphorylate ATM to Phos-S1981ATM were stronger; increased the expression of $\gamma \mathrm{H} 2 \mathrm{AX}$. Compared with the negative groups, these differe-nces would be statistically significant $(p<0.05, p<$ 0.05 ) (Figure 3); After detected, the expression of p-CHK2, p53 and phos-p53 rose with the increasing of $\alpha$-pinene concentration increased ( $p<0.05, p<0.05, p<0.05$ ), but CHK2 had no obvious influence VS control group ( $p>0.05$ ) (Figure 4). Then, compared each content of related protein such as ATM, Phos-S1981ATM, H2AX, $\gamma \mathrm{H} 2 \mathrm{AX}$, Chk2, p-Chk2, p53 and phos-p53 (Figure 5).

\section{Discussion}

DNA damage checkpoints [7] are the important mechanism maintaining stability of the genome in cells, the normal functions of cell cycle checkpoints influence the growth of tissue and organ, aging of cells, occurrence and development of tumor [8] and so on. DNA damage response can active checkpoints in cell cycle and block parts of the cell cycle to ensure enough time to repair damaged DNA [9] and protect the completeness of the genome. ATM is the central member of checkpoints [10] and plays a central regulatory role in multiple steps of cell cycle, especially, ATM has a significant role of monitoring and priming in cell cycle checkpoints and the repair of DNA damage [11].

ATM participates in regulating cell cycle checkpoints and the signal transduction pathway of DNA damage repair [12] by means of phosphorylate and dephosphorylate a series of protein substrates, and stop the damaged

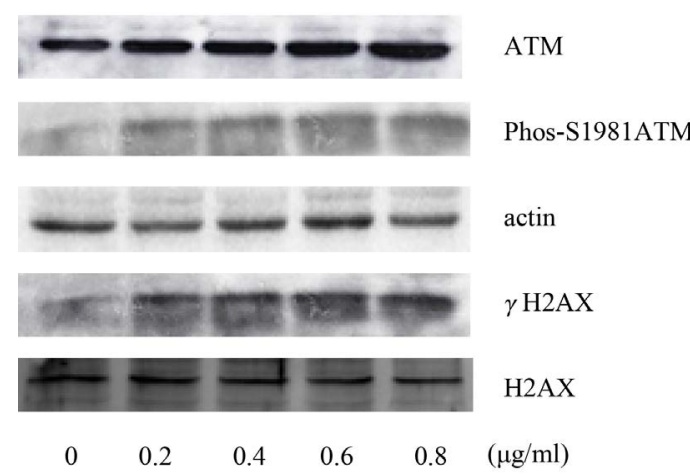

Figure 3. The expression of ATM, H2AX, and phosphorylated protein (after $\alpha$-pinene treated $24 \mathrm{~h}$ ).

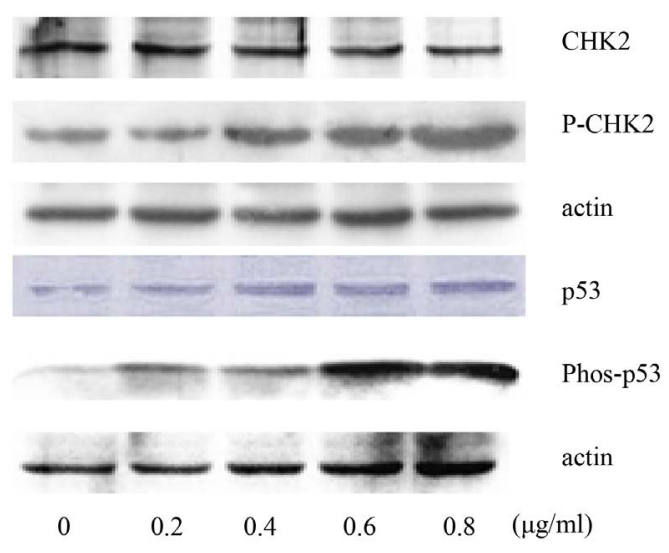

Figure 4. The expression of CHK2, p53 and phosphorylated protein (after $\alpha$-pinene treated $24 \mathrm{~h}$ ). 


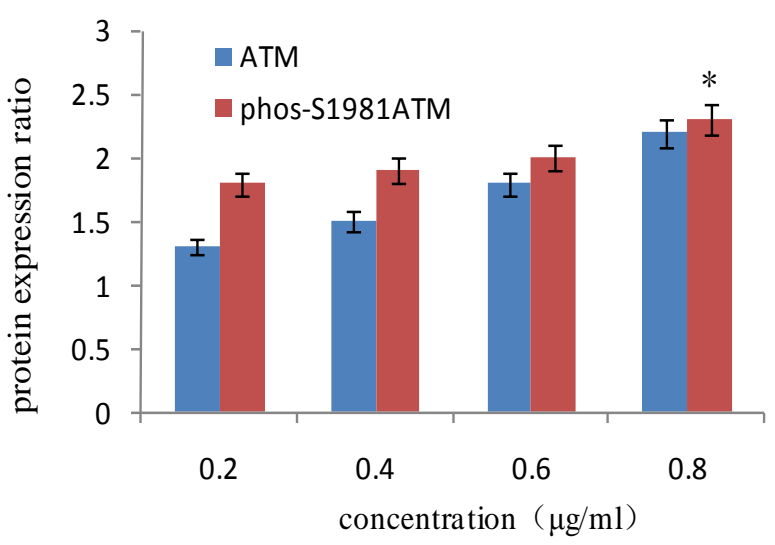

(a)

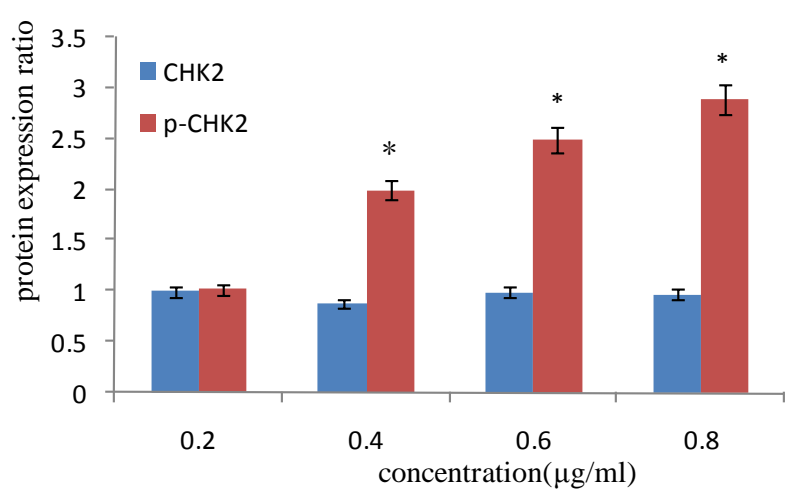

(c)

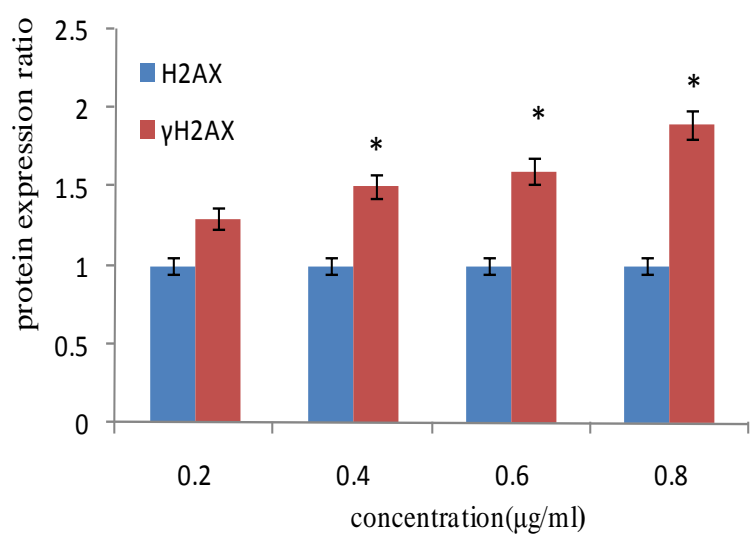

(b)

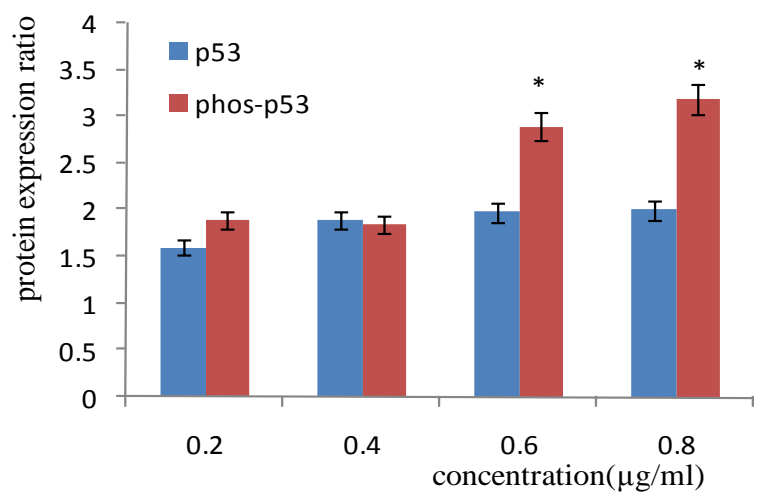

(d)

Figure 5. Different proteins expression ratio in 4 groups of SGC-7901 cells. proteins in four independent experi-ments was quantified against the respective internal reference. a group: when the concentration of $\alpha$-pinene was $0.8 \mu \mathrm{g} / \mathrm{ml}$ the ratio of ATM S1981 phosphorylation had significant difference $(p<0.05)$; b group: when the concen-tration of $\alpha$-pinene was 0.4 $0.8 \mu \mathrm{g} / \mathrm{ml}$ the ratio of $\gamma \mathrm{H} 2 \mathrm{AX}$ had significant difference $(p<0.05)$; c group: when the concentration of $\alpha$-pinene was $0.4-0.8$ $\mu \mathrm{g} / \mathrm{ml}$ the ratio of p-CHK2 significantly different $(p<0.05)$;. d group: when the concentration of $\alpha$-pinene was $0.6,0.8 \mu \mathrm{g} / \mathrm{ml}$ the ratio of phos-p53 significantly different $(p<0.05)$. Data were graphed as means \pm standard errors. ${ }^{*}: p<0.05$ in comparison to control.

DNA at specific checkpoints in the cell cycle and repair it. When various kinds of causes lead to the function of ATM impaired, and cells would lose this function and could not repair the damaged DNA timely. The damaged DNA is prone to enter next generation cells along cell division and generate tumor ultimately. After DNA damaged [13], ATM could be recruited to the site of damaged and caused a series cascade events.ATM active the G1/S phase checkpoint mainly by activating p53 and p21 genes and mediate S phase and G2/M phase checkpoints [14] through activating chk1/chk2 and Cdc25 family members. Besides, ATM is the earliest and also the most important molecule of inducting double-stranded DNA damage. The damaged signal could phosphorylated and active ATM to p-ATM (phosphor-S1981 ATM). Then, p-ATM phosphorylate and active its substrate H2AX become rH2AX. rH2AX is the earliest phosphorylation product and also is the characterictic product in DNA damage response [15] [16]. CHK2 is the main protein downstream of ATM, it would be inactive while it phosphorylated to p-CHK2 by ATM and consequently induces cell cycle arrest [17]. Therefore, we have to detect the variation of ATM and series of related proteins in double-stranded DNA damage before we verify the effect of $\alpha$-pinene on cell cycle.

This experiment adopted that different concentration $\alpha$-pinene impacted on gastric cancer SGC-7901 cells after 24 hours, the inhibition to the cells would grow depending on the concentration within certain range. Then, detecting the content of cell cycle related proteins, such as ATM, Phos-S1981ATM, H2AX, $\gamma$ H2AX, Chk2, p-Chk2, p53 and phos-p53. Our results have shown that, comparing with the control group, the CHK2 phosphorylation content depended on the concentration, but the amount of CHK2 did not be affected. p53 is another key molecule in DNA damage signal pathway, the results indicated that $\alpha$-pinene could up regulated p53 and 
phosphorylate p53 content, it illustrated that there was one signal pathway which rely on p53 in DNA damage response.ATM could phosphorylate and activate $\mathrm{p} 53$, then, signal transduced to downstream target protein and lead to cell cycle blocked eventually. Our research demonstrated that, the checkpoint function of cell cycle disturbed when the expression of ATM deficiency or decreased, and the damaged DNA could not be repaired in time, cell cycle function-blocking weakened. And then, the tumor cells proliferation would enhance as well. The expression of ATM would rise when the concentration of drugs increased, then phosphorylation content of ATM would rise with it and cell cycle blocked. That would make cells having enough time to be repaired and avoid harmful gene spread to next generation. This result indicated that $\alpha$-pinene induced cell cycle arrest might be related to "ATM-p53-p21-CDK1 pathway" [18] and "ATM-CHK2-Cdc25C-CDK1 pathway" [19].

To conclude the study, we could affirm that the inhibiting effect of $\alpha$-pinene on SGC-7901 cells could be mediated by ATM signal pathway preliminary, but some mechanisms for further study are suggested, our researches provide experimental basic for future studies on $\alpha$-pinene that induce the cell cycle arrest of tumor cells.

\section{Research Support}

Innovation Fund of National Science Foundation of China (Project Number: 81201568).

\section{References}

[1] Bhattacharjee, B. and Chatterjee, J. (2013) Identification of Proapoptopic, Anti-Inflammatory, Anti-Proliferative, Anti-Invasive and Anti-Angiogenic Targets of Essential Oils in Cardamom by Dual Reverse Virtual Screening and Binding Pose Analysis. Asian Pacific Journal of Cancer Prevention, 14, 3735-3742.

http://www.apocpcontrol.org/page/apjcp_issues_view.php?sid=Entrez:PubMed\&id=pmid:23886174\&key=2013.14.6.3735 http://dx.doi.org/10.7314/APJCP.2013.14.6.3735

[2] Boohaker, R.J. and Xu, B. (2014) The Versatile Functions of ATM Kinase. Biomedical Journal, 37, 3-9. http://dx.doi.org/10.4103/2319-4170.125655

[3] Kusuhara, M., Urakami, K., Masuda, Y., Zangiacomi, V., Ishii, H., Tai, S., Maruyama, K. and Yamaguchi, K. (2012) Fragrant Environment with $\alpha$-Pinene Decreases Tumor Growth in Mice. Biomedical Research, 33, 57-61. https://www.jstage.jst.go.jp/article/biomedres/33/1/33_1_57/_article

[4] Singh, H.P., Batish, D.R., Kaur, S., Arora, K. and Kohli, R.K. (2006) Alpha-Pinene Inhibits Growth and Induces Oxidative Stress in Roots. Annals of Botany, 98, 1261-1269. http://www.ncbi.nlm.nih.gov/pmc/articles/PMC2803591/ http://dx.doi.org/10.1093/aob/mcl213

[5] Chen, W.-Q., Xu, B., Wei, F.X., Li, M., Liu, T., Jin, X.B. and Zhang, L.R. (2014) Inhibitory Effects of $\alpha$-Pinene on Hepatoma Carcinoma Cell Proliferation. Asian Pacific Journal of Cancer Prevention, 15, 3293-3297. http://www.apocpcontrol.org/page/apjcp issues view.php?sid=Entrez:PubMed\&id=pmid:24815485\&key=2014.15.7.3293

[6] Wajs, A., Urbańska, J., Zaleśkiewicz, E. and Bonikowski, R. (2010) Composition of Essential Oil from Seeds and Cones of Abies alba. Natural Product Communications, 5, 1291-1294.

[7] Wang, B. (2014) Analyzing Cell Cycle Checkpoints in Response to Ionizing Radiation in Mammalian Cells. Methods in Molecular Biology, 1170, 313-320. http://www.ncbi.nlm.nih.gov/pubmed/24906320 http://dx.doi.org/10.1007/978-1-4939-0888-2 15

[8] Ling, H., Lu, L.F., He, J., et al. (2014) Diallyl Disulfide Selectively Causes Checkpoint Kinase-1 Mediated G2/M Arrest in Human MGC803 Gastric Cancercell Line. Oncology Reports, 32, 2274-2282. http://www.spandidos-publications.com/or/32/5/2274

[9] Zeng, Q.Y., Zeng, L.J., Huang, Y., et al. (2014) 8-60hIPP5(m)-Induced G2/M Cell Cycle Arrest Involves Activation of ATM/p53/p21(cip1/waf1) Pathways and Delayed Cyclin B1 Nuclear Translocation. Asian Pacific Journal of Cancer Prevention, 15, 4101-4107. http://www.ncbi.nlm.nih.gov/pubmed/24935604 http://dx.doi.org/10.7314/APJCP.2014.15.9.4101

[10] Zhao, P., Chen, L., Li, L.H., Wei, Z.F., Tong, B., Jia, Y.G., Kong, L.Y., Xia, Y.F. and Dai, Y. (2014) SC-III3, a Novel Scopoletin Derivative, Induces Cytotoxicity in Hepatocellular Cancer Cells through Oxidative DNA Damage and Ataxia Telangiectasia-Mutated Nuclear Protein Kinase Activation. BMC Cancer, 19, 987. http://www.ncbi.nlm.nih.gov/pubmed/25527123

[11] Wei, F., Yan, J. and Tang, D. (2011) Extracellular Signal-Regulated Kinases Modulate DNA Damage Response-A Contributing Factor to Using MEK Inhibitors in Cancer Therapy. Current Medicinal Chemistry, 18, 5476-5482. http://www.ncbi.nlm.nih.gov/pmc/articles/PMC3330700/ http://dx.doi.org/10.2174/092986711798194388 
[12] Sowd, G.A., Mody, D., Eggold, J., Cortez, D., Friedman, K.L. and Fanning, E. (2014) SV40 Tilizes ATM Kinase Activity to Prevent Non-Homologous End Joining of Broken Viral DNA Replication Products. PLoS Pathogens, 10, e1004536. http://www.ncbi.nlm.nih.gov/pubmed/25474690 http://dx.doi.org/10.1371/journal.ppat.1004536

[13] Yao, G., Qi, M., Ji, X., Fan, S., Xu, L., Hayashi, T., Tashiro, S., Onodera, S. and Ikejima, T. (2014) ATM-p53 Pathway Causes G2/M Arrest, but Represses Apoptosis in Pseudolaric Acid B-Treated HeLa Cells. Archives of Biochemistry and Biophysics, 5, 51-60. http://dx.doi.org/10.1016/j.abb.2014.05.029

[14] Wei, F.X., Xie, Y.Y., Tao, L.J. and Tang D. (2010) Both ERK1 and ERK2 Kinases Promote G2/M Arrest in Etoposide-Treated MCF7 Cells by Facilitating ATM Activation. Cellular Signalling, 22, 1783-1789. http://dx.doi.org/10.1016/j.cellsig.2010.07.007

[15] Akihisa, T., Eiichiro, M., Nakagawa, Y., Okamoto, N., Uemura, H., Kondo, N., Noda, T., Toki, A., Ejima, Y., Chen, D.J., Ohnishi, K. and Ohnishi, T. (2010) ATM Is the Predominant Kinase Involved in the Phosphorylation of Histone H2AX after Heating. Journal of Radiation Research, 51, 417-422. http://jrr.oxfordjournals.org/content/51/4/417.long

[16] Mamouni, K., Cristini, A., Guirouilh-Barbat, J., Monferran, S., Lemarié, A., Faye, J.C., Lopez, B.S., Favre, G. and Sordet, O. (2014) RhoB Promotes $\gamma$ H2AX Dephosphorylation and DNA Double-Strand Break Repair. Molecular and Cellular Biology, 34, 3144-3155. http://www.ncbi.nlm.nih.gov/pmc/articles/PMC4135599/ http://dx.doi.org/10.1128/MCB.01525-13

[17] Ma, Y.C., Su, N., Shi, X.J., Zhao, W., Ke, Y., Zi, X., Zhao, N.M., Qin, Y.H., Zhao, H.W. and Liu, H.M. (2015) Jaridonin-Induced G2/M Phase Arrest in Human Esophageal Cancer Cells Is Caused by Reactive Oxygen Species-Dependent Cdc2-tyr15 Phosphorylationvia ATM-Chk1/2-Cdc25C Pathway. Toxicology and Applied Pharmacology, 282, 227-236. http://www.ncbi.nlm.nih.gov/pubmed/25450480 http://dx.doi.org/10.1016/j.taap.2014.11.003

[18] Lossaint, G., Besnard, E., Fisher, D., Piette, J. and Dulić, V. (2011) Chk1 Is Dispensable for G2 Arrest in Response to Sustained DNA Damage When the ATM/p53/p21 Pathway Is Functional. Oncogene, 30, 4261-4274.

http://www.ncbi.nlm.nih.gov/pubmed/21532626 http://dx.doi.org/10.1038/onc.2011.135

[19] Abdel-Fatah, T.M., Arora, A., Alsubhi, N., Agarwal, D., Moseley, P.M., Perry, C., Doherty, R., Chan, S.Y., Green, A.R., Rakha, E., Ball, G., Ellis, I.O. and Madhusudan, S. (2014) Clinicopathological Significance of ATM-Chk2 Expression in Sporadic Breast Cancers: A Comprehensive Analysis in Large Cohorts. Neoplasia, 16, 982-991. http://www.ncbi.nlm.nih.gov/pubmed/25425972 http://dx.doi.org/10.1016/j.neo.2014.09.009 